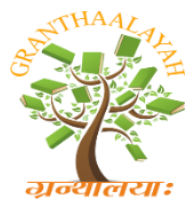

Science

\title{
KNOWLEDGE AND PREVALENCE OF EATING DISORDER AMONG NURSING STUDENTS OF LALITPUR, NEPAL
}

\author{
Suraksha Subedi ${ }^{1}$, Sanjeev Kumar Shah ${ }^{* 2}$, Monika Thapa ${ }^{1}$, Purna Laxmi Maharjan ${ }^{3}$, \\ Purna Devi Shrestha ${ }^{4}$ \\ ${ }^{1}$ Department of Nursing, Asian College for Advance Studies, Purbanchal University, Nepal \\ ${ }^{2}$ National Institute of Health and Environment (NIHE), Kathmandu, Nepal \\ ${ }^{3}$ Department of Public Health, National Open College, Pokhara University, Nepal \\ ${ }^{4}$ National Trauma Center, National Academy of Medical Sciences, Nepal
}

\begin{abstract}
Background: Perceived socio cultural pressure to become thin has an important impact on eating disorder during adolescence, but less is known about knowledge and prevalence of eating disorders in Nepal. Adolescents face special problems that are less common during childhood. Several studies indicate that the prevalence of eating disorders has been increased among adolescents. Objectives: The aim of the study was to identify the level of knowledge, and prevalence of eating disorders (ED) among adolescents. Specific objectives: To calculate the BMI of the respondents and to associate the BMI with prevalence of eating disorder. Methods: This was a cross-sectional survey in which adolescent girls were selected through purposive non probability sampling technique. The study was based on self-reported questionnaires including eating attitudes test (EAT-26) and BMI measurement. To analyze the obtained data, to calculate the level of knowledge, prevalence and BMI the chi-square was measured. Results: According to diagnostic criteria of EAT-26, 34 students (27.2\%) were at risk of ED and scored above the recommended cut-off point on EAT-26. More than fifty percent $(60 \%)$ of the students had inadequate knowledge, one third $(38.40 \%)$ had moderate knowledge and very minimal $(1.6 \%)$ of the students had adequate knowledge regarding eating disorders. BMI calculation reveled that more than half $(54.4 \%)$ had a normal BMI, one third (28\%) were under weight, 16\% were overweight and $1.6 \%$ were obese. Conclusions: The above results concluded that there is need to conduct structured teaching programs for improving level of knowledge regarding eating disorders and reduce the risk of eating disorders and its effects.
\end{abstract}

Keywords: Eating Disorders; Prevalence; Adolescents; EAT; BMI; Nepal.

Cite This Article: Suraksha Subedi, Sanjeev Kumar Shah, Monika Thapa, Purna Laxmi Maharjan, and Purna Devi Shrestha. (2018). "KNOWLEDGE AND PREVALENCE OF EATING DISORDER AMONG NURSING STUDENTS OF LALITPUR, NEPAL.” International Journal of Research - Granthaalayah, 6(4), 179-187. 10.29121/granthaalayah.v6.i4.2018.1642. 


\section{Introduction}

Nutrition is the intake of food, considered in relation to the body's dietary needs.("WHO Nutrition," n.d.) Good nutrition is an adequate, well balanced diet combined with regular physical activity that is a cornerstone of good health.("WHO | Nutrition," n.d.) Poor nutrition can lead to reduced immunity, increased susceptibility to disease, impaired physical and mental development and reduced productivity. ("WHO | Healthy diet," 2017)

Eating disorder is the use of food to satisfy unmet emotional needs, to moderate stress, and to provide rewards or punishment. Further "the inability to regulate eating habits and the frequent tending to overuse or under use food interfere with biological, psychological and socio cultural integrity".(Fairburn \& Beglin, 1994) It is estimated that currently 11\% of high school students have been diagnosed with an eating disorder.(Fairburn \& Beglin, 1994)

The peak age of onset of eating disorder is 15-25 years- i.e. at a developmentally sensitive time.(Government of Nepal \& National Planning Commission, 2017) The average illness duration is about 6 years.(Government of Nepal \& National Planning Commission, 2017) The prevalence of eating disorder behaviors is high in -income countries, especially in combination with obesity.(Government of Nepal \& National Planning Commission, 2017) The eating disorders (anorexia nervosa, bulimia nervosa, binge eating disorder, and related syndromes) are highly distinctive psychiatric disorders. Eating disorders are a category of mental health disorders that affect a person's thoughts and behaviors regarding food and body image. For men, the fatality of eating disorders in Nepal peaks at age 45-49. Women are killed at the highest rate from eating disorders in Nepal at age 45-49.(Government of Nepal \& National Planning Commission, 2017) In Nepal the adolescent population size, age between 15 to 24 years is $21.86 \%$ of total population, in which male is 3176158 and female is 3169721.(Government of Nepal \& National Planning Commission, 2017)

The annual years of healthy life lost per 100,000 people from bulimia nervosa (type of eating disorder) in Nepal has increased by $11.3 \%$ since 1990, an average of $0-5 \%$ a year.(D. K. Thapa \& Thapa, 2015) For men, the health burden of bulimia nervosa in Nepal, as measured in years of healthy life lost per 100,000 men, peaks at age 20-24.(Subash Thapa, 2015) Women are harmed at highest rate from bulimia nervosa in Nepal at age 20-24. At 104.4 years of healthy life lost per 100,000 women in 2013, the peak rate for women was higher than that of men, which was 26.3 per 100,000 men.(D. K. Thapa \& Thapa, 2015)

Adolescents are vulnerable to body image dissatisfaction (BID) and eating disorder, and this vulnerability might differ among females and males. Information about gender differences in prevalence and determinants of body image dissatisfaction and eating disorder in Nepalese adolescents is largely unknown. BID is determined by socio-cultural factors and the analysis of gender is a main factor in the social construction of BID. Traditionally, thick built was perceived as beauty in both genders in Nepalese societies. However, recent criticism stress more on the importance of health, which is thus associated with thinness.(S. Thapa, Thapa, \& Shrestha, 1994) So, Adolescents who are dissatisfied with their body image could indulge themselves in different health compromising behaviors that can lead to inadequate intake of energy and essentials nutrients, thereby jeopardizing growth, development and health. Therefore awareness programs 
through different mass media about negative effects of eating disorder should be stipulated.(S. Thapa et al., 1994)

Eating disorders (EDs) are serious problems among college going women and may be preventable. An inexpensive, easily disseminated intervention might reduce ED onset among those at highest risk.(Schmidt et al., 2016)

In a random student sample, $30 \%$ have eating disorder symptoms or weight concerns.(Bruch, 1974; Khadka et al., 2017; Schmidt et al., 2016) The vast majority of students with symptoms (86.5\%) have not received treatment. On average, students with untreated symptoms have low stigma and high knowledge.(Khadka et al., 2017) The most commonly reported treatment barriers imply lack of urgency/ perceived need. The treatment seeking habits and attitudes of college students, including barriers that may overcome by offering online programs and those that persist despite increased access to and convenience of relevant resources.(Sah, Sah, Shah, \& KC, 2016; Shah et al., 2016; Taylor et al., 2016)

The majorities of individual suffering from eating disorders do not seek or receive adequate professional treatment. Internet -based approaches promise to facilitate access to conventional healthcare by proving an easy-access, low threshold contact.(Hudson, Hiripi, Pope, \& Kessler, 2007; Pengpid, Peltzer, \& Ahsan, 2015)

\section{Material and Methods}

The study design was descriptive study which was focused to the adolescent female of Lalitpur District. This research has tried to analyze the gap between knowledge and prevalence of eating disorder. The sample size of the study was 125 respondents. Nursing school of Lalitpur district was selected by purposive sampling for the feasibility of the researcher as majority of female adolescents are found at nursing school. The standard BMI scale for adolescent female of Asian country was used to collect data. The primary quantitative data was obtained by self-administered questionnaire by using EAT-26 questionnaire (Garner and Garfinkel) for question regarding knowledge of eating disorder and calculation of BMI was done by taking Bio physical measurement like Height and weight. All the female participants between the ages 15-20 years present on the day of collecting data were included in the study. Informed written consent was taken from all the respondents before involving in the study. Ethical clearance was taken from the selected nursing schools (Hope International College and Green Tara College of Health Science Lalitpur, Nepal). All the collected information was entered in SPSS, Percentage and association was done for analysis.

\section{Results}

Total 125 adolescents were participated in this study. 
Table1: Socio Demographic Information, $n=125$

\begin{tabular}{|l|l|l|}
\hline Age (In years) & Frequency & Percent $\mathbf{( \% )}$ \\
\hline $15-17$ & 44 & 35.2 \\
\hline $18-20$ & 81 & 64.8 \\
\hline Religion & Frequency & Percent (\%) \\
\hline Hindu & 101 & 80.8 \\
\hline Buddhist & 17 & 13.6 \\
\hline Christian & 7 & 5.6 \\
\hline Ethnicity & Frequency & Percent (\%) \\
\hline Brahmin/Chhetri & 51 & 40.8 \\
\hline Janajati & 36 & 28.8 \\
\hline Newar & 28 & 22.4 \\
\hline Dalit & 7 & 5.6 \\
\hline Tarai/Madheshi & 3 & 2.4 \\
\hline Total & 125 & 100.0 \\
\hline & &
\end{tabular}

Table 1 illustrates that the majority $(64.8 \%)$ of the respondent belongs to 18-20 years age group and one third (35.2\%) respondent belongs to $15-17$ years age group. The majority $(80.8 \%)$ of respondent followed Hinduism and least (5.6\%) of the respondent followed Christianity. Among the ethnicity, less than fifty percent $(40.8 \%)$ of the respondent were Brahmin/Chhetri and the least $(2.4 \%)$ respondent were Terai/Madheshi.

Table 2: Distribution of Respondent According to their BMI, $\mathrm{n}=125$

\begin{tabular}{|l|l|l|}
\hline Characteristics & Frequency & Percent (\%) \\
\hline Under weight & 35 & 28.0 \\
\hline Normal & 68 & 54.4 \\
\hline Over weight & 20 & 16.0 \\
\hline Obese & 2 & 1.6 \\
\hline Total & 125 & 100.0 \\
\hline
\end{tabular}

Table 2 illustrates that more than half $(54.4 \%)$ of the respondent had normal BMI and very few $(1.6 \%)$ of the respondent were obese. 
Table 3: Distribution of Respondent According to their Stressful life Event, $n=125$

\begin{tabular}{|c|c|c|c|}
\hline \multirow[t]{2}{*}{ Stressful Life Event } & \multicolumn{2}{|c|}{ Responses } & \multirow[b]{2}{*}{ Percent of Cases (\%) } \\
\hline & $\mathbf{N}$ & Percent $(\%)$ & \\
\hline Not present & 80 & 60.6 & 64.0 \\
\hline Death of family member & 33 & 25.0 & 26.4 \\
\hline Chronic illness & 12 & 9.1 & 9.6 \\
\hline Single Parent & 6 & 4.5 & 4.8 \\
\hline Divorce of Parents & 1 & .8 & .8 \\
\hline Total & 132 & 100 & 105.6 \\
\hline
\end{tabular}

Table 3 illustrates that the majority $(64.6 \%)$ of the respondent had no any stressful life event in their life and least $(0.8 \%)$ of the respondent had divorced parents.

Table 4: Family History of Eating Disorder, $\mathrm{n}=125$

\begin{tabular}{|l|l|l|}
\hline Family History & Frequency & Percent $(\boldsymbol{\%})$ \\
\hline Not present & 93 & 74.4 \\
\hline Siblings & 20 & 16.0 \\
\hline Mother & 6 & 4.8 \\
\hline Aunt & 3 & 2.4 \\
\hline Cousin Sister & 3 & 2.4 \\
\hline Total & 125 & 100.0 \\
\hline
\end{tabular}

Table 4 highlights that the majority (74.4\%) of the respondents had no any family history of eating disorder and least $(2.4 \%)$ respondent had eating disorder among their cousin and aunt.

Table 5: Level of Knowledge on Eating Disorders, $n=125$

\begin{tabular}{|l|l|l|}
\hline Characteristics & Frequency & Percent (\%) \\
\hline Inadequate & 75 & 60.0 \\
\hline Moderate & 48 & 38.4 \\
\hline Adequate & 2 & 1.6 \\
\hline Total & 125 & 100.0 \\
\hline
\end{tabular}

Source: Self-administered questionnaire regarding knowledge of eating disorders. Table 6 illustrates more than half $(60 \%)$ of the respondent had inadequate knowledge, one third $(38.4 \%)$ had moderate and least $(1.6 \%)$ of the respondent had adequate knowledge.

To calculate the level of knowledge UNDP- EAT-26, 2016 was used. 
Table 6: Prevalence of Eating Disorders, $n=125$

\begin{tabular}{|l|l|l|}
\hline Prevalence & Frequency & Percent $\mathbf{( \% )}$ \\
\hline Absence & 91 & 72.8 \\
\hline Presence & 34 & 27.2 \\
\hline Total & 125 & 100.0 \\
\hline
\end{tabular}

Table 7: Association of BMI with Prevalence of Eating Disorders, $\mathrm{n}=125$

\begin{tabular}{|c|c|c|c|c|c|}
\hline \multicolumn{2}{|c|}{ BMI Category } & \multicolumn{2}{|c|}{ Prevalence } & \multirow[t]{2}{*}{ Total } & \multirow{2}{*}{$\begin{array}{c}\text { Chi-square } \\
\text { (P-value) }\end{array}$} \\
\hline & & Presence & Absence & & \\
\hline \multirow[t]{2}{*}{ Under weight } & Frequency (n) & 8 & 27 & 35 & \multirow{10}{*}{0.210} \\
\hline & Percentage (\%) & 22.9 & 77.1 & 100.0 & \\
\hline \multirow[t]{2}{*}{ Normal } & Frequency (n) & 16 & 52 & 68 & \\
\hline & Percentage $(\%)$ & 23.5 & 76.5 & 100.0 & \\
\hline \multirow[t]{2}{*}{ Over weight } & Frequency $(\mathrm{n})$ & 9 & 11 & 20 & \\
\hline & Percentage $(\%)$ & 45.0 & 55.0 & 100.0 & \\
\hline \multirow[t]{2}{*}{ Obese } & Frequency (n) & 1 & 1 & 2 & \\
\hline & Percentage $(\%)$ & 50.0 & 50.0 & 100.0 & \\
\hline \multirow[t]{2}{*}{ Total } & Frequency (n) & 34 & 91 & 125 & \\
\hline & \begin{tabular}{|l|} 
Percentage $(\%)$ \\
\end{tabular} & 27.2 & 72.8 & 100.0 & \\
\hline
\end{tabular}

Source: based on self-administered questionnaire on EAT-26. Table 17 illustrates the majority (72.8\%) of the respondent had absence of eating disorder and nearly one fourth $(27.2 \%)$ had eating disorder.

Table 7 illustrates that there is no significant association between BMI and prevalence of eating disorders.

\section{Discussion}

A very limited research has been done on eating disorders in Nepal. Recent studies conducted in Nepal, examined eating disorders among adolescents of randomly selected 10 private higher secondary school of Kathmandu in 2015, identified a prevalence of $29 \%$ eating disorders in female and $16 \%$ in male. This research was well supported by this study because the prevalence of eating disorders in this study is $27.2 \%$ and the tools used for identifying the prevalence were same that is EAT-26.(D. K. Thapa \& Thapa, 2015) Both studies were conducted in Kathmandu valley and educational level were equal and the age group were same.

More than fifty $(60.0 \%)$ of the respondent had inadequate knowledge and (38.4\%) had moderate knowledge and only a least $(1.6 \%)$ had adequate knowledge regarding eating disorders. Likewise study conducted in India among medical students of Narayan Medical college Hospital revealed that majority $(87 \%)$ of the adolescent girl had inadequate knowledge and the remaining $13 \%$ had moderate knowledge regarding eating disorders.(Sansone, Levitt, \& Sansone, 2004; Zlotnick, 
Mattia, \& Zimmerman, 2001) This finding shows that the level of knowledge regarding eating disorders is slightly higher in Nepalese Nursing students' comparison to Narayan Medical College Students of India, it may be due to limited knowledge related questions in this study and also a different form of question structure used.(Furth, Meer, \& Cowan, 2016; Lipson et al., 2017)

Study conducted in Bangladesh in 2014 revealed that $37.6 \%$ of university students had eating disorders and in multivariate analysis late adolescent $17-19$ years were highly involved. Where as in this study the 18-19 years age group students were highly involved and that is $64.8 \%$. Study conducted in Karachi Pakistan in 2012 revealed that $22.75 \%$ had eating disorder and among them $87.90 \%$ female and $12.10 \%$ male. In this study the prevalence of eating disorders among female adolescent was $27.2 \%$ which is at similar age group.(Pengpid et al., 2015) So this study focused only in most vulnerable group considering the age and sex factor. BMI calculation shows that $28 \%$ were underweight $54.40 \%$ had normal BMI, $16 \%$ were overweight and $1.6 \%$ were obese. Study conducted in 2012 in Karachi Pakistan calculate the BMI of adolescent girls and the result was 9\% were severely underweight, $4 \%$ underweight, $41.10 \%$ normal, $7.6 \%$ over weight and $0.9 \%$ belongs to obese.(Sansone et al., 2004; Shah et al., 2016; Zlotnick et al., 2001) This result indicates that the pattern of BMI is similar in both countries it may be due to country's economic structure, as both are developing countries.

BMI is significant predictor of eating disorders and it was well supported by this study. However this study found no association of BMI with eating disorders, as well as no association of eating disorders with level of knowledge.(Babalola \& Fatusi, 2009; Basnet, Hinderaker, Enarson, Malla, \& Mørkve, 2009)

\section{Conclusion}

In western countries there are number of research done and appropriate programs have been initiated and implemented regarding this problem, whereas on the other hand, in South East Asian countries that is very limited research and recently that has been started. Previously the problem of eating disorders was thought to be the problems of western societies. However, several studies have clearly demonstrates that eating disorders is leading serious psychological and nutritional consequences in Asia.

It has been concluded that the risk factors for eating disorders are gender (more common in girls), age (more common in adolescent or early adulthood), heredity or family history, Media influence, occupation etc. and there is no specific region for eating disorders.

As in others non-western countries the prevalence of eating disorders in Nepal is as same level. Research conducted by Thapa, D. \& Thapa, S. suggested that there is large percentage of adolescent girls who are suffering from eating disorders and they need medical help as well as proper counseling and health education as well planned education program to prevent and cure the eating disorders.(Subash Thapa, 2015) 


\section{Acknowledgement}

Our sincere thanks goes to Asian College for Advance Studies, Hope International College, and Green Tara College of Health Science for the opportunity and the help rendered to carry out the investigation. We would also like to thank to the people who gave valuable contribution with enormous support in ideal discussion. We are thankful to Ms. Jennifer Mathias for their valuable comments. We would like to thank all college authorities and students who participated in the study.

Funding: No funding sources

Conflict of interest: None declared

Ethical approval: The study was approved by the Department of Research \& Development, Asian College for Advance Studies, Purbanchal University, Nepal. Written permission was obtained from the appropriate authorities and written consent was obtained from study participants.

\section{References}

[1] Babalola, S., \& Fatusi, A. (2009). Determinants of use of maternal health services in Nigeria looking beyond individual and household factors. BMC Pregnancy and Childbirth, 9, 43. https://doi.org/10.1186/1471-2393-9-43

[2] Basnet, R., Hinderaker, S. G., Enarson, D., Malla, P., \& Mørkve, O. (2009). Delay in the diagnosis of tuberculosis in Nepal. BMC Public Health, 9, 236. https://doi.org/10.1186/1471-2458-9-236

[3] Bruch, H. (1974). Eating disorders. Obesity, anorexia nervosa, and the person within. Eating Disorders. Obesity, Anorexia Nervosa, and the Person Within. Retrieved from https://www.cabdirect.org/cabdirect/abstract/19741422333

[4] Fairburn, C. G., \& Beglin, S. J. (1994). Assessment of eating disorders: Interview or self-report questionnaire? International Journal of Eating Disorders, 16(4), 363-370. https://doi.org/10.1002/1098-108X(199412)16:4<363::AID-EAT2260160405>3.0.CO;2-\#

[5] Furth, E. F. van, Meer, A. van der, \& Cowan, K. (2016). Top 10 research priorities for eating disorders. The Lancet Psychiatry, 3(8), 706-707. https://doi.org/10.1016/S2215-0366(16)30147-X

[6] Government of Nepal, \& National Planning Commission. (2017, March). Demography of Nepal 2016: Trends and Policy Implications. Retrieved March 11, 2018,

[7] Hudson, J. I., Hiripi, E., Pope, H. G., \& Kessler, R. C. (2007). The Prevalence and Correlates of Eating Disorders in the National Comorbidity Survey Replication. Biological Psychiatry, 61(3), 348-358. https://doi.org/10.1016/j.biopsych.2006.03.040

[8] Khadka, K., Shah, S. K., Ts, S., Mathias, J., Upadhayay, A., Ghimire, R., \& Ghimire, S. (2017). Knowledge and Awareness about Cervical Cancer Screening and HPV Vaccine among Females Aged 15-49 Years in Rukum District of Nepal. American Journal of Cancer Prevention, 5(1), 10 16. https://doi.org/10.12691/ajcp-5-1-2

[9] Lipson, S. K., Jones, J. M., Taylor, C. B., Wilfley, D. E., Eichen, D. M., Fitzsimmons-Craft, E. E., \& Eisenberg, D. (2017). Understanding and promoting treatment-seeking for eating disorders and body image concerns on college campuses through online screening, prevention and intervention. Eating Behaviors, 25, 68-73. https://doi.org/10.1016/j.eatbeh.2016.03.020

[10] Pengpid, S., Peltzer, K., \& Ahsan, G. U. (2015). Risk of eating disorders among university students in Bangladesh. International Journal of Adolescent Medicine and Health, 27(1), 93-100. https://doi.org/10.1515/ijamh-2014-0013 
[11] Sah, B. K., Sah, J. P., Shah, S. K., \& KC, A. (2016). Knowledge on Tuberculosis among Students of Higher Secondary School, Lalitpur, Nepal. MOJ Public Health, 4(5), 1-11. https://doi.org/10.15406/mojph.2016.4.00091

[12] Sansone, R. A., Levitt, J. L., \& Sansone, L. A. (2004). The Prevalence of Personality Disorders Among Those with Eating Disorders. Eating Disorders, 13(1), 7-21. https://doi.org/10.1080/10640260590893593

[13] Schmidt, U., Adan, R., Böhm, I., Campbell, I. C., Dingemans, A., Ehrlich, S., ... Zipfel, S. (2016). Eating disorders: the big issue. The Lancet. Psychiatry, 3(4), 313-315. https://doi.org/10.1016/S2215-0366(16)00081-X

[14] Shah, S. K., Shetty, S. K., Singh, D. R., Mathias, J., Upadhayay, A., \& Pandit, R. (2016). Prevalence of Undernutrition among Musahar Children Aged Between 12 To 59 Months in Urban Siraha District, Nepal. MOJ Public Health, 4(5), 1-7. https://doi.org/10.15406/mojph.2016.4.00093

[15] Taylor, C. B., Kass, A. E., Trockel, M., Cunning, D., Weisman, H., Bailey, J., ... Wilfley, D. E. (2016). Reducing eating disorder onset in a very high risk sample with significant comorbid depression: A randomized controlled trial. Journal of Consulting and Clinical Psychology, 84(5), 402-414. https://doi.org/10.1037/ccp0000077

[16] Thapa, D. K., \& Thapa, S. (2015). Gender Differences in Body Image Dissatisfaction and Eating Disorder among Nepalese Adolescents: a Paradigm Shift from Fatness to Thinness. Clinical Psychiatry, Vol. 1 No. 2:12.

[17] Thapa, S., Thapa, P. J., \& Shrestha, N. (1994). Abortion in Nepal: emerging insights. Advances in Population: Psychosocial Perspectives, 2, 253-270.

[18] Thapa, Subash. (2015). Gender Differences in Body Image Dissatisfaction and Eating Disorder among Nepalese Adolescents: a Paradigm Shift from Fatness to Thinness. Clinical Psychiatry, 1(2). https://doi.org/10.21767/2471-9854.100012

[19] WHO | Healthy diet. (2017, September). Retrieved March 11, 2018, from http://www.who.int/mediacentre/factsheets/fs394/en/

[20] WHO | Nutrition. (n.d.). Retrieved March 11, 2018, from http://www.who.int/topics/nutrition/en/

[21] Zlotnick, C., Mattia, J. I., \& Zimmerman, M. (2001). The Relationship Between Posttraumatic Stress Disorder, Childhood Trauma and Alexithymia in an Outpatient Sample. Journal of Traumatic Stress, 14(1), 177-188. https://doi.org/10.1023/A:1007899918410

*Corresponding author.

E-mail address: just4sanjeev@ gmail.com 